\title{
Computer Teaching Development Based on Information Environment
}

\author{
Yan Hou \\ Qilu Normal University, Ji'nan, Shandong, 250014, China
}

Keywords: Information environment; Computer teaching; Development

\begin{abstract}
Informatization of education sector mainly means to utilize computer and network to display teaching content in a new form or utilize computer and network to extend the knowledge learned. In one word, computer and network are applied in practical teaching to make teaching more convenient and effective. Besides, this can motivate students' learning interest, and improve students' autonomous learning ability and comprehensive abilities. In information environment, the implementation of information-based education becomes an inexorable trend. This paper mainly discusses computer teaching development under information environment, in the hope of providing some teaching data for education workers.
\end{abstract}

\section{Introduction}

At present, society has entered global informatization. Informatization turns into the basis of national and regional development degree. Meanwhile, it is a mark to manifest national comprehensive strength and level. Education industry as the foundation of national development is a cradle to cultivate talents foe the society, so it should be more cutting-edge. Although computer teaching system has been improved gradually and strives to integrate with informatization, some bad phenomena still exist. For example, teaching contents are simplified; theoretical knowledge is focused on; practical skill and ability are ignored. Under general environment of informatization, computer teachers should reform original teaching, get rid of traditional defects and introduce informatization in teaching.

\section{Necessity of teaching material reform}

As information era develops at a high speed, teaching must advance with the times. Main carriers of informatization are intangible network and tangible computer equipment. Wide application of computer teaching under information environment needs to be based on computer knowledge and application, while knowledge acquisition mostly comes from teaching materials. Practical knowledge is updated fast, while knowledge in teaching materials is updated slowly. Thus, original teaching materials cannot adapt computer teaching in information era. Thus, it is required to rationally reform original teaching materials to make them adapt computer teaching. The reform of teaching materials should be targeted and planned, and cannot be conducted blindly. Teaching materials should be prepared in allusion to students at different age to make them adapt the needs of right-age students. In this way, the teaching requirement that students act as the subject can be met, and students can get rid of teachers' infusion mode and give play to their thinking ability and creation ability ${ }^{[1]}$.

The reform of computer teaching material should pay attention to knowledge structure and cultivating students' divergent thinking ability so that students can continuously think during reading textbooks, motivate their potential and expand limited textbook knowledge.

The purpose of computer teaching material reform is to adapt era development and teaching demand. Thus, teaching material reform must adapt to era development so as to enable computer teaching material reform to satisfy educational informatization. Application of network and computer in class is also a manifestation of adding informatization in computer teaching material ${ }^{[2]}$. Such teaching mode can literate students' thinking, adapt teaching requirements in different stages, effectively improve China's teaching level and achieve integration with international information-based teaching in continuous reform and perfection ${ }^{[3]}$. 


\section{Setup of diversified teaching mode under information environment}

Under information environment, it is required to reform computer teaching materials, learning environment and teaching mode to achieve diversified teaching mode. Diversified teaching mode means to complete teaching through multiple sensory stimuli so that students can remember knowledge more deeply. In English teaching, teachers may adopt multimedia teaching mode to play image and sound via multimedia so as to make dull knowledge become visual and three-dimensional. Through visual and auditory stimulus, students' listening, speaking and reading abilities can improve. Relative to traditional teaching, such teaching mode can better drive students' learning atmosphere so that students can take the initiative to learn and motivate their learning interest. At present, some universities have introduced multimedia teaching in practical teaching, gained good effects and highlighted the help and influence of information age on teaching.

\section{Computer teaching means under information environment}

Computer teaching can improve teachers' teaching efficiency and extend teaching knowledge. Since computer can autonomously control course content and operation, fast seek and handle documents. Besides, the same teaching content can be transmitted among different computers so that teaching information can be effectively utilized. In computer technology teaching process, dull knowledge on textbooks can be shown in vivid and dynamic form. Meanwhile, the knowledge can be simulated, judged and reasoned according to teaching content. The accuracy of students' answer can be distinguished so as to effectively guide students.

Computer teaching can make teaching more flexible. Learning content and schedule can be chosen according to students' basic level; learning mode can be chosen according to students' learning ability; proper learning schemes can be offered according to students' individuality. All these can optimize teaching. Students with different level and ability can gain corresponding teaching resource and mode. This greatly helps to cultivate students' individuality. Computer teaching can effectively record students' learning process. Teachers score students' performance according to students' earning execution information, and then give targeted guidance for students. Students can keep learning process in computer teaching, and teachers can monitor and know students' learning state via computer. Therefore, such teaching mode contributes to improving students' attention. In traditional teaching, if students miss the content taught by the teacher, it is hard for them to review it. But under computer teaching conditions, students can repeat to learn the same knowledge until they totally master the knowledge. Computer teaching totally follows the principle of regarding students as teaching subject. Students adopt active form in teaching activity, and learn more relaxingly, which can enhance learning effect.

Computer application cannot be separated from development and utilization of teaching software. Under certain hardware conditions, software quality exerts a direct influence on teaching effect. Teaching software can play an assistant role in teaching and replace teachers to execute teaching task to some extent. Firstly, software can assist teaching. Software can display textbook knowledge in the form of dynamic image and clear sound via computer, and make abstract knowledge vivid and make complex knowledge concrete. Secondly, teaching software executes teaching task. Students can choose the content complying with their knowledge level and ability through teaching software application. However, such learning mode is only limited to lesson review, for the knowledge provided by computer is mechanical and breaks away from teachers' guidance, and students may easily enter learning misunderstanding. Teaching software owns timeliness. Hence, teachers should update teaching software in time. At the same time, the most important function of teaching software is assisted instruction, so teachers cannot excessively depend on computer, but fully excavate their internal potential to make them better assist in teaching. 


\section{Computer multimedia teaching measure under information environment}

The significance of computer multimedia teaching measure is that, computer and traditional teaching mode may be combined to complete teaching objective. Characters, images and data on textbooks are transformed to dynamic image and sound through application of computer technology to optimize teaching effect. In traditional teaching, knowledge utilization level is limited, and knowledge content cannot be displayed three-dimensionally from multiple angles. Thus, students' understanding of knowledge is limited. Multimedia teaching makes up for defects in traditional education, displays teaching information overall and meets the demand of combing audio-visual media and man-machine teaching ${ }^{[4]}$.

If multimedia is introduced in teaching, teachers may make teaching course according to teaching material, adjust plane knowledge in teaching materials according to teaching needs and make knowledge become dynamic and three-dimensional knowledge structure. Students can learn learning schedule according to their own learning degree.

Psychological study finds that different people differ a lot in auditory memory and visual memory. According to traditional teaching method, teachers adopt “cramming” teaching means, and students listen to teachers passively. In this way, for the students with poor auditory memory and good visual memory, learning effect may be affected. Multimedia teaching effectively combines multimedia teaching and visual sense, which can meet memory demand of all students. Through stimulus of two sense organs, students' memory can be deepened.

Some teaching contents involve acoustic information. Especially in primary school teaching, students' knowledge and understanding ability is limited, and cannot perceive specific expression form of sound from teachers' description. At this time, teachers may utilize multimedia to restore text description to real sound. For example, the article Listen, The Sound of The Autumn (PEP edition, Grade 3 of Chinese in primary school) involves the sound of big tree shaking its arm and the sound of cricket flapping its wings. It is very difficult for teachers to really show the sound through teachers' simulation, while multimedia can help teachers solve this teaching difficulty. In addition, such novel teaching means can motivate students' learning interest and improve teaching effect.

Insertion of dynamic images in teaching can help students better understand knowledge and solve problems. Dynamic image can turn written narration into more visual and three-dimensional content. For example, Car A and Car B go to three-dimensional from South Station at the same time. Car A runs $14 \mathrm{~km}$ more than Car B per hour. After Car A runs for 5.5h and arrives at North Station, it returns at once without any delay along the original way and encounters with Car B at 32.5km away from North Station. How many kilometers does Car A run? It is very hard for elementary school students to understand this question. Teachers may utilize multimedia to show motion of the two cars. In this way, students can easily understand the meaning and then answer it.

\section{Computer network teaching method under information environment}

Computer network teaching can offer great convenience for teaching. Computer network can make teaching materials shared, which extends computer use mode and teaching content. Single computer teaching cannot form enormous network resource sharing, and teachers cannot know students' learning. Thus, teachers can neither master students' knowledge level nor guide them correctly. Computer network teaching can provide huge teaching information resource library for teachers and students, and students can seek the knowledge they need via network so as to increase knowledge reserve. Teachers may know and master students' study on computer via linking network and then give students corresponding guidance and help. Meanwhile, students can make timely response to teachers in case of any problem in study, which facilitates exchange between students and teachers. Computer network teaching can accurately record students' learning schedule and quality. Teachers may analyze and evaluate students' study through the information and then formulate scientific teaching scheme. This contributes to improving teaching effect.

Computer network teaching can achieve cross-space dialogue, and there is no teaching time limit. Students can learn, contact and test online anytime and anywhere, and consult teachers of famous 
universities. Students can make study plan according to their learning need and learning status, and transform traditional passive study to active study so as to improve students' enthusiasm and learning efficiency. Moreover, teachers may modify online teaching information anytime and anywhere according to actual conditions so as to keep on perfecting network teaching.

\section{Teaching examination means under information environment}

In information environment, corresponding examination means should keep pace with teaching development after computer teaching is optimized, so it is necessary to optimize and reform examination means by computer technology. Firstly, sound computer examination system should be established, and assessment system should be perfected continuously to finally dorm a set of computer teaching examination system conforming to information environment. Secondly, computer examination system greatly differs from traditional examination system. Hence, during computer examination design, teachers should combine computer teaching to rationally design examination items and requirements to make computer examination adopt computer teaching. Thirdly, uniform standard test should form in computer examination, and computer grading mode is adopted to reduce manual mistakes so that students' scores are more real and talent selection is fairer. Finally, computer examination software should be deeply developed. Besides, multiple evaluation modes should be brought in computer examination to make student evaluation more scientific, rational and comprehensive. At the same time, network communication channel should be established to let parents gain students' scores in a timely and accurate way, promote communication between teachers and parents and make parents participate. In this way, students' study and character development can be more all-round.

\section{Conclusions}

In conclusion, our education work should keep pace with the era in information environment. Computer technology can be introduced in teaching to enrich teaching means, motivate students' learning interest and improve their learning efficiency through multiple sensory stimuli. Meanwhile, teachers should keep on perfecting computer teaching to make sensory stimuli better applied in teaching. But teachers should not ignore the leading position of their teaching. Furthermore, teachers should establish computer examination mechanism to make it matched with computer teaching.

\section{References}

[1] Zhu Hongwei, Yang Errui, Study on Computer Teaching Development Based on Information Environment. Technology Wind, 2013(11):182-182.

[2] Yang Chang, Computer Network Teaching Based on Information Environment. Office Automation (Academic Edition), 2013(12):54-55.

[3] He Yuxuan, Reasonable Implementation of Computer Teaching and Making A Information-based Technology Power. Urban Construction and Commercial Outlets, 2009(30):228-229.

[4] Chen Lijun, On Information-based Teaching Design of Computer Teaching. Heilongjiang Science and Technology Information, 2014(10):109-109. 